\title{
A global data set of soil hydraulic properties and sub-grid variability of soil water retention and hydraulic conductivity curves
}

\author{
Carsten Montzka $^{1}$, Michael Herbst ${ }^{1}$, Lutz Weihermüller ${ }^{1}$, Anne Verhoef ${ }^{2}$, and Harry Vereecken ${ }^{1,3}$ \\ ${ }^{1}$ Forschungszentrum Jülich GmbH, Institute of Bio- and Geosciences: Agrosphere (IBG-3), Jülich, Germany \\ ${ }^{2}$ University of Reading, Department of Geography and Environmental Science, Reading, UK \\ ${ }^{3}$ International Soil Modeling Consortium, Jülich, Germany
}

Correspondence to: Carsten Montzka (c.montzka@fz-juelich.de)

Received: 14 February 2017 - Discussion started: 23 February 2017

Revised: 19 June 2017 - Accepted: 19 June 2017 - Published: 27 July 2017

\begin{abstract}
Agroecosystem models, regional and global climate models, and numerical weather prediction models require adequate parameterization of soil hydraulic properties. These properties are fundamental for describing and predicting water and energy exchange processes at the transition zone between solid earth and atmosphere, and regulate evapotranspiration, infiltration and runoff generation. Hydraulic parameters describing the soil water retention (WRC) and hydraulic conductivity (HCC) curves are typically derived from soil texture via pedotransfer functions (PTFs). Resampling of those parameters for specific model grids is typically performed by different aggregation approaches such a spatial averaging and the use of dominant textural properties or soil classes. These aggregation approaches introduce uncertainty, bias and parameter inconsistencies throughout spatial scales due to nonlinear relationships between hydraulic parameters and soil texture. Therefore, we present a method to scale hydraulic parameters to individual model grids and provide a global data set that overcomes the mentioned problems. The approach is based on Miller-Miller scaling in the relaxed form by Warrick, that fits the parameters of the WRC through all sub-grid WRCs to provide an effective parameterization for the grid cell at model resolution; at the same time it preserves the information of sub-grid variability of the water retention curve by deriving local scaling parameters. Based on the Mualem-van Genuchten approach we also derive the unsaturated hydraulic conductivity from the water retention functions, thereby assuming that the local parameters are also valid for this function. In addition, via the Warrick scaling parameter $\lambda$, information on global sub-grid scaling variance is given that enables modellers to improve dynamical downscaling of (regional) climate models or to perturb hydraulic parameters for model ensemble output generation. The present analysis is based on the ROSETTA PTF of Schaap et al. (2001) applied to the SoilGrids $1 \mathrm{~km}$ data set of Hengl et al. (2014). The example data set is provided at a global resolution of $0.25^{\circ}$ at https://doi.org/10.1594/PANGAEA.870605.
\end{abstract}

Hydraulic properties have fundamental importance in the description of water, energy and carbon exchange processes between the land surface and the atmosphere (e.g. Ek and Cuenca, 1994; Xue et al., 1996). Therefore, agroecosystem models (e.g. SWAP; van Dam et al., 2008) and land surface models (LSMs; see below) require adequate parameterization of soil hydraulic properties - i.e. more specifically, the water retention curve (WRC) and the hydraulic conductivity curve (HCC). These properties regulate the relative magnitude of water balance fluxes such as evapotranspiration, infiltration and surface and sub-surface runoff (Vereecken et al., 2016), and thus the amount of water held in the soil at any one time. As well as affecting the water balance components, they also play a role in the land surface energy balance - directly via their effect on latent heat flux (evapotranspiration, e.g. via available soil water influencing plant water 
stress; see Verhoef and Egea, 2014), and indirectly because the size of the evapotranspiration co-determines land surface temperature, that in turn affects net radiation, sensible heat flux and soil heat flux (the latter is also affected via soil moisture dependency of soil thermal properties). With regard to the carbon balance, photosynthesis and soil respiration both strongly depend on soil moisture content and hence implicitly on choice of soil hydraulic models and their parameters.

State-of-the-art LSMs, e.g. NOAH (Niu et al., 2011), CLM (Oleson et al., 2008), VIC (Liang et al., 1994), JULES (Best et al., 2011) and ORCHIDEE (Ngo-Duc et al., 2007), are key components of regional and global climate models (RCMs/GCMs) and numerical weather prediction models (NWPMs). They form important components of reanalyses (e.g. ERA-Interim/Land; Balsamo et al., 2015) and modeldata assimilation systems, such as the NASA Land Information System (LIS) or the Global Land Data Assimilation System (GLDAS; Rodell et al., 2004). LSMs solve Richard's equation for the water flow in the saturated/unsaturated zone. A fundamental problem is the adequate parameterization of the water retention and hydraulic conductivity function to solve Richard's equation. At point scale, a broad suite of experimental methods are available that allow measuring the WRC and HCC. These measurements are, however, expensive and time consuming, and often comprise intensive field sampling campaigns. Alternatively, parameters of the WRC and HCC can be estimated from in situ or remotely sensed data in combination with parameter estimation techniques (Scharnagl et al., 2011; Bauer et al., 2012; Dimitrov et al., 2014; Jadoon et al., 2012; Montzka et al., 2011). At larger scales, such as those where RCMS and GCMs are employed, the WRC and HCC are impossible to estimate (because underlying soil properties vary widely within grid cells) and are unobtainable by direct measurements.

To overcome this problem, the estimation of the required soil hydraulic properties is usually based on pedotransfer functions (PTFs) that use simple soil properties such as texture, organic matter and bulk density to derive the parameters of mathematical equations that describe the HCC and the WRC (Vereecken et al., 2010). The idea behind PTFs is that more easily available soil data such as soil texture, soil organic carbon content or bulk density can be used to predict the hydraulic parameters for the WRC and HCC. In the last three decades, soil scientists have developed a broad suite of PTFs that differ with respect to the parameterizations of soil hydraulic properties for which they are used, the type of soil properties needed as inputs to derive the model-dependent parameters, and their spatial patterns. PTFs were developed for the prediction of parameters used in the Campbell (1974) family of hydraulic functions (e.g. Clapp and Hornberger, 1978), Brooks and Corey (1964) (e.g. Rawls and Brakensiek, 1985), and Mualem-van Genuchten equations (e.g. Rawls and Brakensiek, 1985; Vereecken et al., 1989; Scheinost et al., 1997; Wösten et al., 1999; Weynants et al., 2009; Toth et al., 2015). Bouma (1989) distinguished between two types of PTFs, namely continuous and class type PTFs. Continuous PTFs use information on textural properties, bulk density and soil organic matter amongst others, whereas class type PTFs do not estimate the parameters based on continuous textural and other soil properties but estimate the parameters for defined textural classes - e.g. 12 USDA textural classes (Clapp and Hornberger, 1978; Toth et al., 2013). The disadvantage of the latter is that only the class average can be predicted and inner-class variability is neglected.

Another issue with the soil hydraulic parametrization in LSMs is caused by the spatial resolution of the model application under consideration (e.g. GCM runs for reanalyses or NWP model runs for weather forecasts), which is currently several (tens of) kilometres. This means that the soil input parameters to be provided at this scale have to be derived from existing data sources. Unfortunately, intrinsic soil properties are highly variable in space; in most cases several soil types can be found within a single grid cell of GCMs, for example. These soil types often differ strongly in soil texture, soil organic carbon content and bulk density, and soil depth and layering. Consequently, the fine-scale soil information, available from state-of-the-art soil maps such as the European LUCAS (Land Use/Land Cover Area Frame Survey) (Toth et al., 2013; Ballabio et al., 2016) at $500 \mathrm{~m}$ resolution or the global SoilGrid database at $1 \mathrm{~km}$ resolution (Hengl et al., 2014), has to be up-scaled to the scale at which the LSMs are being employed. The general problem of up-scaling, or change in spatial resolution of the input data by aggregating small-scale input data, and the resulting output uncertainty for various model states was reported, for example, by Cale et al. (1983), Rastetter et al. (1992), Pierce and Running (1995), Hoffmann et al. (2016), and Kuhnert et al. (2016). A practical example is GLDAS2-NOAH, where the porosity and the percentages of sand, silt and clay at the original scale of the input data from Reynolds et al. (2000) were horizontally resampled, i.e. spatially averaged, to the $0.25^{\circ}$ GLDAS grid (Rodell et al., 2004). Despite their importance, only a few studies investigating the implications of the above-mentioned issues (up-scaling, aggregation or resampling) on the model results have been conducted in the past.

The most straightforward method to aggregate input parameters from small-scale soil maps to larger-scale grid cells of a GCM would be spatial averaging. For some soil properties such as soil organic carbon, bulk density, or soil depth this kind of approach seems reasonable, whereas for soil texture averaging it is associated with considerable problems. For example, a GCM grid cell containing a pure sand soil for half of its area with the other half a pure clay would provide a sandy clay on average, which neither adequately reflects the sand nor the clay soil physical properties. Additionally, averaging percentages may cause artefacts in closing the mass balance. A second method would be the averaging of soil hydraulic parameters (e.g. the van Genuchten parameters), whereby Zhu and Mohanty (2002) clearly showed that averaging of especially the shape parameters ( $a$ and $n$ ) is associ- 
ated with considerable uncertainty. A third and most widely used aggregation technique for soil inputs at coarse model resolution is the one based on dominant soil types, where the dominant soil type within a coarse grid cell is derived from the fine-scale soil map. However, in using this approach some information will get lost in the GCM outputs because nondominant, but physically very differently behaving soils will not be taken into account during the model runs. In consequence, fluxes from non-dominant areas of the grid cell will not be reproduced at large scale.

The theory introduced by Miller and Miller (1956) provided a technique to scale the relationships of pressure head and hydraulic conductivity by considering microscopic laws for capillary pressure forces and viscous flow in porous media based on a similarity assumption of the pore space structure (Warrick et al., 1977). Similarity scaling allows converting hydraulic characteristics (e.g. pressure head or conductivity) of one system (e.g. a soil sample) or location (e.g. a point scale measurement of WRC at field scale) towards corresponding characteristics of another system or location (Tillotson and Nielsen, 1984) under the condition that the internal geometry of the system only differs by size. MillerMiller scaling therefore allows capturing the spatial variability of soil hydraulic properties in one single scaling parameter rather than having to specify the statistics for each single hydraulic parameter (Warrick et al., 1977). The set of scaling factors (i.e. each location or sample has one scaling factor) follow approximately a log-normal distribution (Simmons et al., 1979). Tuli et al. (2001) analysed a physically based scaling approach of unsaturated hydraulic conductivity and soil water retention functions from pore size distribution. They assumed that the relationship between both characteristics is log-normally distributed and that pores are geometrically similar, and showed that in this case scaling factors computed from median pore size or capillary pressure head can be used to describe the variability of unsaturated hydraulic conductivity functions. Using a fractal model, Pachepsky et al. (1995) showed that the spatial variability of water retention functions could be described by the spatial variability of a single dimensionless parameter. Ahuja et al. (1984) found that scaling factors for different soil depths are also related, and Clausnitzer et al. (1992) investigated the potential to simultaneously scale the WRC and HCC and found evidence that the results do not necessarily require independent scaling. In more detail, Hendrayanto et al. (2000) showed that separate scaling resulted in large estimation errors in either effective saturation or hydraulic conductivity. Further scaling methods have been developed based on the fractal method, e.g. the piecewise fractal approach proposed by Millan and Gonzalez-Posada (2005) or the wavelet transform modulus maxima introduced by Zeleke and $\mathrm{Si}$ (2007). Wang et al. (2009), as well as Fallico et al. (2010), analysed the multifractal distribution of scaling parameters for soil water retention characteristics. Shu et al. (2008) stressed the need for location-dependent scale analyses to improve the performance for soil water retention characteristic predictions. Jana and Mohanty (2011) showed that a Bayesian neural network can be applied across spatial scales to approximate fine-scale soil hydraulic properties. With this approach ground-, air-, and space-based remotely sensed geophysical parameters directly contribute to a PTF in a single processing step instead of aggregating/scaling the estimated parameters to other scales in an independent second step. Recently, Fang et al. (2016) established an amplification factor for soil hydraulic conductivity to compensate for the resulting retardation of water flow due to the loss of information content as a consequence of spatial aggregation. Liao et al. (2014) pointed out that uncertainty in the soil water retention parameters mainly results from the limited number of samples used for deriving PTFs and the spatial interpolation of basic soil properties. However, the latter error contribution dominates the potential to correctly determine spatial parameters, which leads to the assumption for our study that existing PTFs provide adequate parameters for global model applications. Nevertheless, the scaling uncertainty still needs to be considered.

The objectives of this study are therefore as follows: (i) to apply the Miller-Miller scaling approach to the state-of-theart soil data set SoilGrids $1 \mathrm{~km}$ to provide a global consistent soil hydraulic parameterization for GCMs based on first principles; these soil hydraulic parameterizations can be used in models of the terrestrial system to predict soil water fluxes based on solving Richard's equation from local to global scale; (ii) to present a method to identify the sub-grid variability of WRC and HCC with reference to the $1 \mathrm{~km}$ resolution SoilGrids $1 \mathrm{~km}$ soil texture database - this scaling information can be used to perturb hydraulic parameters to generate ensemble runs with GCMs or to improve GCM downscaling; (iii) to evaluate the performance of the scaling approach for the calculation of the WRCs and HCCs against standard aggregation procedures based on two exemplary grid cells with varying variability in textural properties; and finally (iv) to demonstrate the importance of the scaling variance at different spatial resolutions for three larger regions in North America, Africa and Asia. We provide the corresponding aggregated global data set for the ROSETTA PTF (Schaap et al., 2001) at $0.25^{\circ}$ regular grid spacing at https://doi.org/10.1594/PANGAEA.870605.

\section{Material and methods}

In this section the database and the approach to generate the global data set of soil hydraulic parameters is presented (see also Fig. 1). In the following, all analyses are based on the SoilGrids $1 \mathrm{~km}$ database in combination with ROSETTA (Schaap et al., 2001). Other soil databases and PTFs can be used similarly. The PTF will be applied to the high-resolution soil texture maps to predict high-resolution Mualem-van Genuchten $(\mathrm{MvG})$ parameters. These are then scaled to cal- 


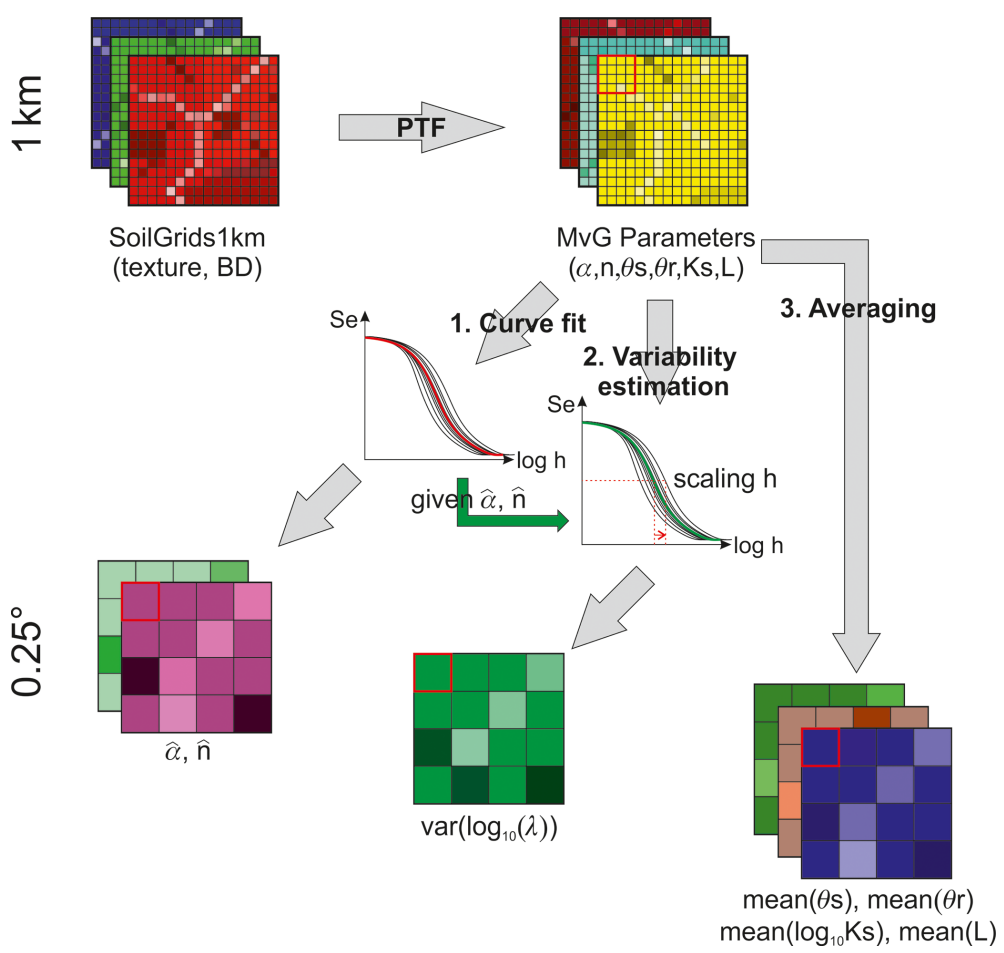

Figure 1. Proposed method to aggregate soil hydraulic properties and sub-grid variability of soil water retention and hydraulic conductivity curves.

culate soil hydraulic properties for the WRCs and HCCs employed at a coarser scale. In Sect. 2.3, the scaling approach is explained, and additionally the treatment of the sub-grid variance will be presented. In Sect. 2.4 details about the application to generate the global data set are given.

\subsection{SoilGrids $1 \mathrm{~km}$}

The SoilGrids $1 \mathrm{~km}$ database (Hengl et al., 2014) is a consistent, coherent and global data set created by automated mapping (Vereecken et al., 2016). The main inputs are publicly available soil profile data, such as the USA National Cooperative Soil Survey Soil Characterization database (NCSS), the Land Use/Cover Area frame Statistical Survey LUCAS (Toth et al., 2013), and the Soil and Terrain Database (SOTER) (Van Engelen and Dijkshoorn, 2012). Moreover, additional information, derived from moderate-resolution imaging spectroradiometer (MODIS) satellite imagery and the Shuttle Radar Topography Mission (SRTM) digital elevation model, has been used. Artificial surfaces as well as bare rock areas, water bodies, shifting sands, permanent snow and ice were neglected. The resulting soil properties at seven predefined depths $(0,5,15,30,60,100$ and $200 \mathrm{~cm})$ are soil organic carbon $\left(\mathrm{g} \mathrm{kg}^{-1}\right)$, soil $\mathrm{pH}$, sand, silt, and clay fractions (\%), coarse fragments (gravel) (\%), bulk density $\left(\mathrm{kg} \mathrm{m}^{-3}\right)$, cation-exchange capacity $\left(\mathrm{cmol}^{+} \mathrm{kg}^{-1}\right)$, soil organic carbon stock $\left(\mathrm{tha}^{-1}\right)$, depth to bedrock $(\mathrm{cm})$, World Reference Base soil groups and USDA Soil Taxonomy sub- orders. SoilGrids $1 \mathrm{~km}$ implements model-based geostatistics and multiple linear regressions for predicting sand, silt and clay percentages, and bulk density, as well as general linear models with log-link function for predicting organic carbon content. Lower and upper confidence limits at $90 \%$ probability of the predictions are also provided. In theory, the full prediction uncertainty could be used to estimate soil hydraulic property uncertainty but in our study we restricted the analysis on the mean predicted values. The findings of Hengl et al. (2014) indicate that the distribution of soil organic carbon content in horizontal direction is mainly controlled by climatic conditions (temperatures and precipitation), while the distribution of texture is mainly controlled by topography and lithology. The advantage of SoilGrids $1 \mathrm{~km}$ over other soil databases is that it provides pixel-based information rather than gridded vector information from classbased vector polygons. It should be noted that SoilGrids $1 \mathrm{~km}$ is stored in a World Geodetic System 84 (WGS84) regular grid with $1 \mathrm{~km}$ resolution at the equator. The resolution at other latitudes is therefore higher.

\subsection{Pedotransfer functions, water retention and hydraulic conductivity functions}

A global high-resolution hydraulic parameters data set is needed to infer the scaling characteristics for large-scale climate models. Based on the textural information stored in the SoilGrids $1 \mathrm{~km}$ database, PTFs can directly estimate the 
required hydraulic parameters (Fig. 1). Several PTFs have been developed; here, we focus on the widely used PTF ROSETTA model H3 by Schaap et al. (2001), which is based on neural network predictions for the estimation of the Mualem-van Genuchten (MvG) parameters $\theta_{\mathrm{s}}, \theta_{\mathrm{r}}, \alpha, n, K_{\mathrm{S}}$ and $L$ (van Genuchten, 1980), whereby the WRC to describe the effective volumetric saturation $S_{\mathrm{e}}$ is calculated according to

$$
\begin{aligned}
S_{\mathrm{e}}(h) & =\frac{\theta-\theta_{\mathrm{r}}}{\theta_{\mathrm{s}}-\theta_{\mathrm{r}}} \\
& \left\{\begin{array}{cc}
1 & h \geq 0 \\
{\left[1+(\alpha|h|)^{n}\right]^{-m}} & h<0, \alpha, m>0, n>1,
\end{array}\right.
\end{aligned}
$$

where $\theta_{\mathrm{r}}\left(\mathrm{cm}^{3} \mathrm{~cm}^{-3}\right)$ and $\theta_{\mathrm{s}}\left(\mathrm{cm}^{3} \mathrm{~cm}^{-3}\right)$ are the residual and saturated volumetric water content, respectively, and $\alpha$ $\left(\mathrm{cm}^{-1}\right), n(-)$ and $m(-)\left(m=n-\frac{1}{n}\right)$ are shape parameters. Finally, the MvG approach to describe the HCC is given by

$K(h)=K_{\mathrm{S}} S_{\mathrm{e}}^{L}\left[1-\left(1-S_{\mathrm{e}}^{1 / m}\right)^{m}\right]^{2}$,

where $K(-)$ is the unsaturated hydraulic conductivity, $K_{\mathrm{S}}$ $\left(\mathrm{cm} \mathrm{d}^{-1}\right)$ is the saturated hydraulic conductivity and $L$ is the pore connectivity parameter (-).

In a first step, ROSETTA was used to predict the MvG parameters based on the textural information of the SoilGrid map for each $1 \mathrm{~km}$ cell. In a next step, the water retention pairs $\left(S_{\mathrm{e}}\right.$ versus $\left.h\right)$ were calculated for predefined pressure heads $h(\mathrm{~cm})$ using the pressure head vector $\boldsymbol{h}$ :

$$
\begin{aligned}
\boldsymbol{h} & =[-1,-5,-10,-20,30,-40,-50,-60,-70,-90,-110 \\
& -130,-150,-170,-210,-300,-345,-690,-1020, \\
& -5100,-15300,-20000,-100000,-1000000]
\end{aligned}
$$

The pressure heads in $\boldsymbol{h}$ were chosen to reflect pressure steps commonly used in laboratory analysis. We assumed $-300 \mathrm{~cm}$ to reflect field capacity whereas wilting point $(h \sim-1500 \mathrm{~cm})$ is generally found between -1020 and -5100 . In $\mathrm{pF}$ terms $\left(\log _{10}(\boldsymbol{h})\right)$ the $\boldsymbol{h}$ vector went up to 6 .

\subsection{Scaling approach and sub-grid variability estimation}

In this study, the Warrick et al. (1977) scaling approach is applied to the parameters derived from the SoilGrids $1 \mathrm{~km}$ data for each soil depth separately. The procedure characterizes scaling factors to relate the hydraulic properties at a specific location to the mean hydraulic properties at a reference point or a point representative for a larger region.

In a first step we need to find adequate parameters for the retention function at the coarse scale (Fig. 1). This approach has been reported in Clausnitzer et al. (1992). For each subpixel $i$ the relative saturation $S_{\mathrm{e}_{i}}$ is calculated by

$S_{\mathrm{e}_{i}}(\boldsymbol{h})=f\left(\boldsymbol{h}, \alpha_{i}, n_{i}\right)=\left[1+\left(\alpha_{i}|\boldsymbol{h}|\right)^{n_{i}}\right]^{-m_{i}}$.
Next, the coarse-scale parameters $\hat{\alpha}$ and $\hat{n}$ of the water retention curve $f\left(h, \alpha_{i} n_{i}\right)$ need to be found that minimize the sum of squares of the deviations for all respective subpixels $i=1 \ldots N$, with $N$ being the number of subpixels within the coarse grid cell:

$(\hat{\alpha}, \hat{n})=\sum_{i=1}^{N}\left[S_{\mathrm{e}_{i}}-f\left(\boldsymbol{h}, \alpha_{i}, n_{i}\right)\right]^{2}$.

The parameter fitting algorithm used in this study was the damped least-squares method of Levenberg-Marquardt (LM) (Marquardt, 1963) to find a global minimum. As initial values for LM fitting, the grid-specific spatial average of $\alpha(\bar{\alpha})$ and $n(\bar{n})$ was used.

Russo and Bresler (1980), as well as Warrick et al. (1977), showed that scale factors for soil water retention and unsaturated hydraulic conductivity are not necessarily identical. However, Clausnitzer et al. (1992) reported that an independent fitting would lead to inconsistencies in the parameter space, and that a single scaling factor is well suited to describe the distribution and correlation structure of HCC and WRC. In this study we use the relationship between $K_{\mathrm{r}}$ and $S_{\mathrm{e}}$ in Eq. (2). Therefore, the scaling of the WRC can be directly transferred to the HCC, by using $\hat{\alpha} \hat{n}$ from Eq. (5), even though these scaling parameters might not be the optimum choice for the HCC. However, this approach was chosen for simplicity - to allow for easy handling of hydraulic parameters via a single scaling parameter for global Earth system model applications. For the coarse grid cell representative HCC the missing parameters $K_{\mathrm{S}}$ and $L$ are spatially averaged from the sub-grid parameters - in the case of $K_{\mathrm{s}}$ in logarithmic space. Similarly, $\theta_{\mathrm{s}}$ and $\theta_{\mathrm{r}}$ were also spatially averaged, i.e. for the coarse resolution $\overline{\theta_{\mathrm{s}}}$ and $\overline{\theta_{\mathrm{r}}}$ were calculated.

In a second step, the sub-grid variability is estimated by introducing the scale parameter $\lambda$ to the hydraulic head vector to simplify the description of the statistical variation of soil properties (Fig. 1). This is done by

$\boldsymbol{h}^{*}=\frac{\boldsymbol{h}}{\lambda}$.

After substituting $\boldsymbol{h}$ by $\boldsymbol{h}^{*}$ in the van Genuchten (1980) water retention function (Eq. 4), while using previously estimated $\hat{\alpha}$ and $\hat{n}$, only the scaling factor is fitted for each individual subpixel. Equation (5) can then be rewritten as

$\left(\hat{\lambda_{i}}\right)=\sum_{i=1}^{\mathrm{N}}\left[S_{\mathrm{e}_{i}}-f\left(\boldsymbol{h}, \hat{\alpha}, \hat{n}, \lambda_{i}\right)\right]^{2}$.

Equation (7) is subject to the constraint that the coarse grid mean of the set of scaling factors is unity $\left(\frac{1}{N} \sum_{i=1}^{N} \log _{10}\left(\hat{\lambda_{i}}\right)=0\right)$. This constraint is already approximated by adequately fitting of $\hat{\alpha}$ and $\hat{n}$ in the first step. Again, similar to the first step, the unsaturated HCC is scaled based on the parameters estimated for the WRC.

We recommend calculating the variance of the logarithmic $\hat{\lambda_{i}}$ as a parameter of sub-grid variability for further use. The sub-grid variability information $\operatorname{var}\left(\log _{10} \hat{\lambda_{i}}\right)$ can be used in 
further research to perturb the soil hydraulic parameterization in ensemble runs of climate or weather prediction models.

\subsection{Global application}

The scaling method proposed here is applied to the parameters derived from the whole SoilGrids $1 \mathrm{~km}$ data set. In this study, every terrestrial coarse grid cell is identified with a unique ID, where the SoilGrids $1 \mathrm{~km}$ attribution to the coarse cell was performed within a GIS system. This ensures flexibility to predict parameters for any type of grid, no matter whether it is approximately isotropic, such as in the MetOffice Global Atmosphere 4.0 and Global Land 4.0 model (Walters et al., 2014), or an unstructured mesh of hexagonal/triangular grid cells in the Ocean-Land-Atmosphere Model (OLAM) (Walko and Avissar, 2008). We chose a spatial resolution of $0.25^{\circ}$, as used, for example, in GLDASNOAH (Rodell et al., 2004). One coarse grid cell contains exactly $30 \times 30=900$ fine-resolution pixels. The number of fine-resolution pixels used for calculating the scaling statistics is also provided with the data set, because lakes and broad rivers reduce the number of relevant pixels. In addition, for global application a land-sea mask has been established to omit irrelevant pixels. The final data set is delivered for latitudes ranging from -60 to $90^{\circ}$, omitting Antarctica.

\subsection{Analysis procedure}

In this section the procedure is explained concerning how the final data set of hydraulic parameters and scaling information was evaluated. This was done by selecting sample regions for a detailed presentation of the data set performance. Two coarse grid cells of different sub-grid heterogeneity were selected and the scaling results for the WRCs and HCCs compared discussed. The importance of considering sub-grid variability is stressed for different spatial resolutions by means of three larger regions.

\subsubsection{Detailed grid cells analysis}

In order to investigate the performance of the scaling approach in more detail, two coarse grid cells within Germany were selected based on an initial analysis of the sub-grid sand standard deviation (Fig. 2).

The focus on German sites is motivated by the large variation in soil texture, from a heterogeneous region in the north of Germany to a relatively homogeneous region in the German central lowlands. Moreover, the quantity of soil profile information contribution to the SoilGrids $1 \mathrm{~km}$ neural network approach is quite high in these regions. The first grid cell was selected in the south of Lower Saxony where Pleistocene morainal plains turn into Jurassic and Triassic rocks. This region exhibits small-scale differences in rocks and sediments where the soils developed from. The second region selected

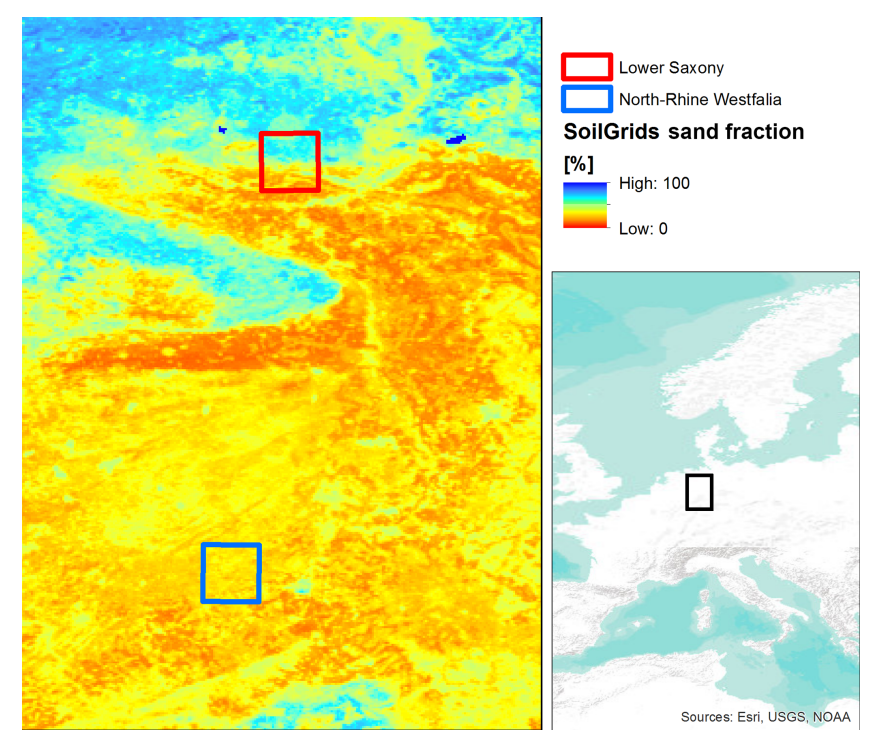

Figure 2. Location of the $0.25^{\circ}$ test pixels in Germany, and their sand fraction based on SoilGrids $1 \mathrm{~km}$.

is located in the southeast of North Rhine-Westphalia where the soil developed from Devonian weathered rocks as well as fluviatile sediments from the Rhine River system. This region can be regarded to be relatively homogeneous in soil texture. See also the soil texture diagrams in Fig. 3.

In order to compare our results to other commonly applied aggregation schemes, we also calculated the WRCs and HCCs (i) by averaging soil texture information and then using the ROSETTA equations; (ii) by averaging MvG parameters directly; (iii) by identifying the dominant USDA soil class for each coarse grid cell and then utilizing classrepresentative MvG parameters; and (iv) by identifying the dominant USDA soil class for each coarse grid cell and then utilizing the Clapp and Hornberger (1978) approach to calculate the hydraulic properties, which requires dedicated hydraulic parameters. The Clapp and Hornberger (1978) parameterization is based on the Campbell approach (Campbell, 1974) for calculation of water retention and unsaturated hydraulic conductivity. This approach has been added to illustrate the differences between the MvG and Campbell (1974) approach that is still often used in GCM. $S_{\mathrm{e}_{\text {Camp }}}$ after Campbell (1974) is given by

$S_{\mathrm{e}_{\text {Camp }}}(h)=\frac{\theta}{\theta_{\mathrm{S}}}\left\{\begin{array}{cl}1 & h \geq h_{\mathrm{B}} \\ \left(\frac{1}{h_{\mathrm{B}}}|\boldsymbol{h}|\right)^{-\frac{1}{b}} & h<h_{\mathrm{B}},\end{array}\right.$

where $h_{\mathrm{B}}$ is the air entry value and $b$ is the pore size distribution index (-). The related hydraulic conductivity function for Campbell (1974) is given by

$K_{\mathrm{r}, \text { Camp }}(h)=K_{\mathrm{s}}\left(\frac{\theta(h)}{\theta_{\mathrm{S}}}\right)^{(3+2 b)}$. 

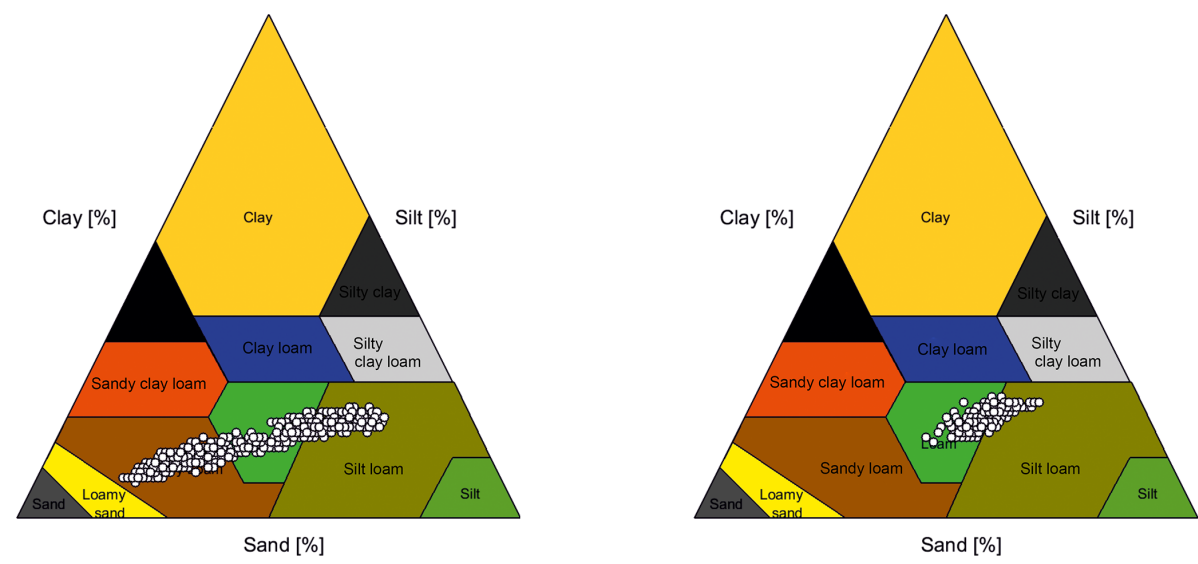

Figure 3. Soil texture triangles, illustrating the difference in soil textural variability of the Lower Saxony pixel (left) and the North RhineWestphalia pixel (right), according to USDA classification.

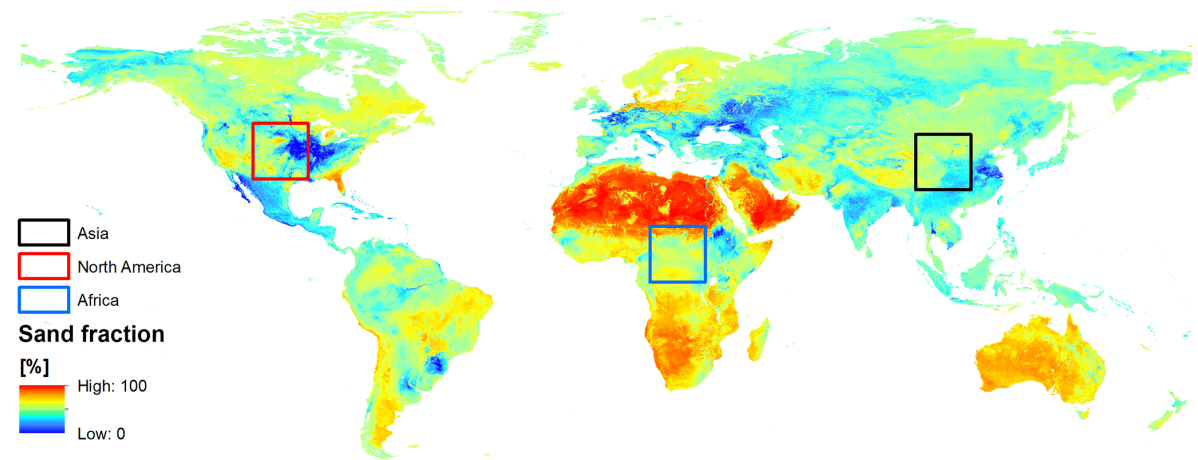

Figure 4. Example regions selected to evaluate the scaling variance loss from Warrick scaling at different spatial resolutions when neglecting the scaling variance. The background shows the sand fraction from SoilGrids $1 \mathrm{~km}$.

Note that the Campbell approach is similar to the Brooks and Corey (1964) approach - the only difference is that the latter did not set $\theta_{\mathrm{r}}=0$ in the WRC. Also, Clapp and Hornberger (1978) did not consider $\theta_{\mathrm{r}}$ in their equations.

\subsubsection{Analysis of scaling variability for different spatial resolutions}

In order to stress the importance of considering the subgrid scaling information provided by the proposed method, the mean $\operatorname{var}\left(\log _{10} \hat{\lambda_{i}}\right)$ is quantified for different spatial resolutions. Three regions were analysed in more detail - namely regions in North America, central Africa and China/Mongolia consisting of $2048 \times 2048$ fine pixels from the SoilGrids $1 \mathrm{~km}$ database (see Fig. 4). For each of these larger regions a single parameter set of $\hat{\alpha}$ and $\hat{n}$ is estimated by using Eq. (5). For each fine $1 \mathrm{~km}$ pixel the scaling parameter $\hat{\lambda_{i}}$ is calculated according to Eq. (7). Different resolutions of $2,4,8,16,32,64,128,256,512$ and $1024 \mathrm{~km}$ were applied to the resulting map of $\hat{\lambda}_{i}$. For each spatial resolution the cell-specific scaling parameter is averaged $\left(\operatorname{mean}\left(\log _{10} \hat{\lambda_{i}}\right)\right)$.
Finally, the variance of these averaged scaling parameters is calculated for the large regions. Herein we hypothesize that the variance of the scaling parameter is a function of spatial resolution.

This analysis uses the original SoilGrids $1 \mathrm{~km}$ spatial resolution as a reference. However, it has to be mentioned that the calculated scaling variability only refers to the information content of the SoilGrid $1 \mathrm{~km}$ reference, and does not necessarily provide the real soil scaling variability.

\section{Results and discussion}

For brevity in this paper the results for the top soil layer are discussed only. After a description of the global data set, this section discusses the results for the two example pixels in Germany and the influence of different spatial resolutions on the variability of three larger regions. This discussion is followed by an analysis of the uncertainties related to the data set. 

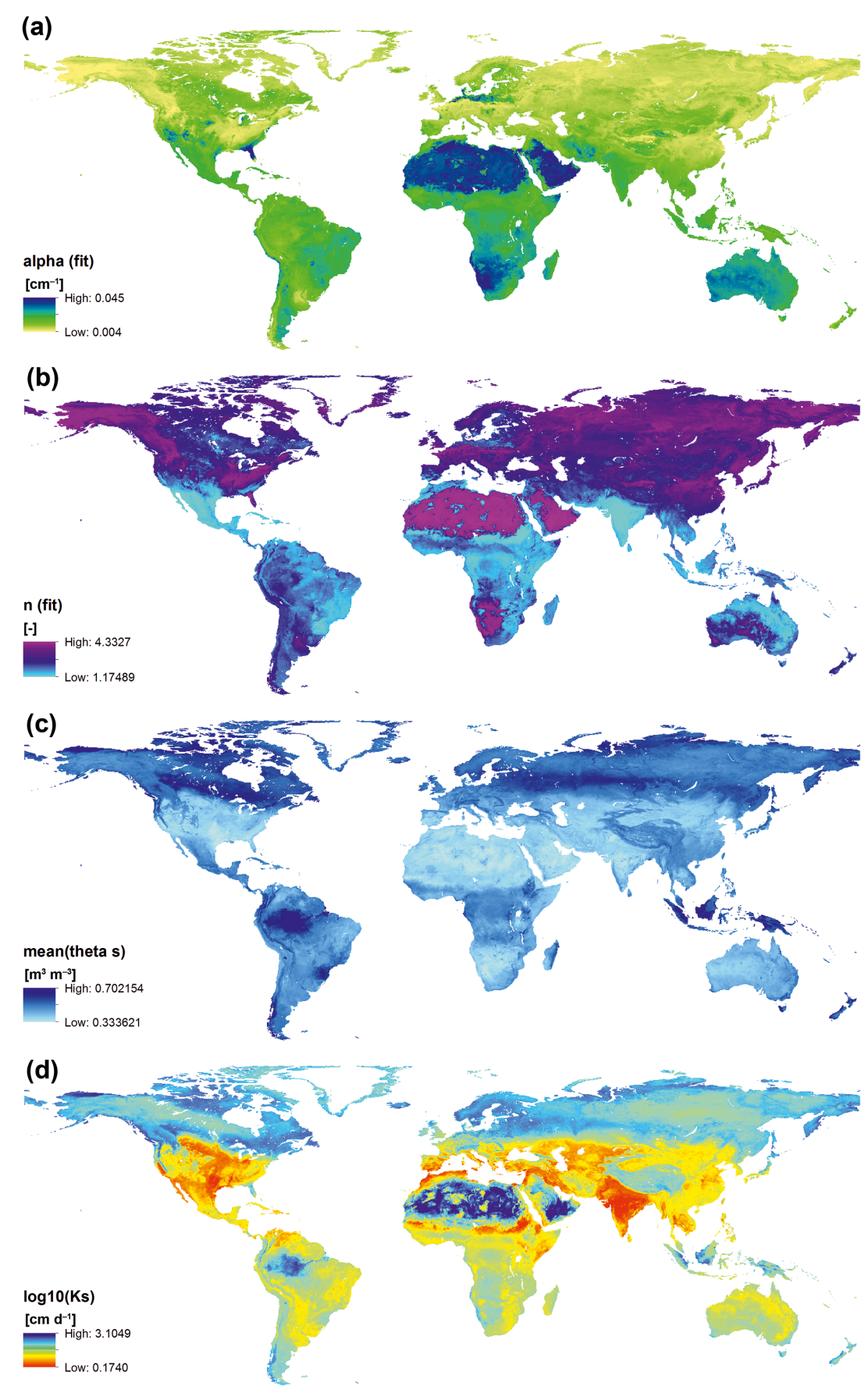

Figure 5. Global map of $\hat{\alpha}(\mathbf{a}), \hat{n}(\mathbf{b}), \overline{\theta_{\mathrm{S}}}(\mathbf{c})$ and mean $\left(\log _{10}\left(K_{\mathrm{S}}\right)\right)(\mathbf{d})$, as derived when using the SoilGrids $1 \mathrm{~km}$ data set as input to the Rosetta PTF (Schaap et al., 2001), at $0.25^{\circ}$ spatial resolution.

\subsection{Global analysis}

The resulting global hydraulic parameters $\hat{\alpha}, \hat{n}, \overline{\theta_{\mathrm{s}}}$ as well as mean $\left(\log _{10} K_{\mathrm{S}}\right)$ are presented in Fig. 5. Parameter $\hat{\alpha}$ ranges between 0.0036 and $0.045 \mathrm{~cm}^{-1}$ with a global average of $0.0143 \mathrm{~cm}^{-1}$ and shows a clear biogeographical or climatic related distribution. Relatively low values can be found mainly under boreal forests, but also in the North China
Plain, central Europe, US Midwest and the Cordoba province in Argentina. Especially the low bulk density of boreal top soils in the SoilGrids $1 \mathrm{~km}$ database, and their widespread occurrence, reduce the global average of $\hat{\alpha}$ to that low value. Relatively high values of $\hat{\alpha}$ were found at locations with high sand fractions, such as the desert regions of the Sahara, the Namib, and the Arabian Peninsula, and to a lesser extent also 


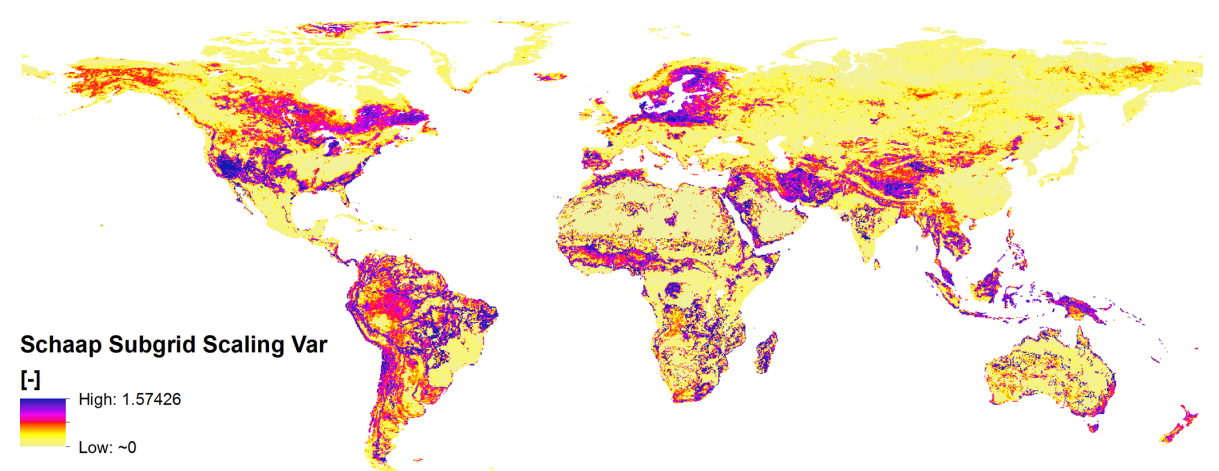

Figure 6. Global map of $\operatorname{var}\left(\log _{10} \hat{\lambda_{i}}\right)$ calculated from SoilGrids $1 \mathrm{~km}$ data set and the Rosetta PTF (Schaap et al., 2001) for $0.25^{\circ}$ resolution.

Table 1. Variables stored in the final data set. The variable $z$ indicates the soil depth, i.e. $z \in[0,5,15,30,60,100,200] \mathrm{cm}$.

\begin{tabular}{llll}
\hline Variable & Units & Explanation & Variable name \\
\hline Latitude & Decimal degree & Latitude in degrees north, Southern Hemisphere in negative numbers & Latitude \\
Longitude & Decimal degree & Longitude in degrees east, west of Greenwich in negative numbers & Longitude \\
$\hat{\alpha}$ & $\mathrm{cm}^{-1}$ & Fitted $\alpha$ at $z \mathrm{~cm}$ depth for MvG parameterization & alpha_fit_zcm \\
$\hat{n}$ & - & Fitted $n$ at $z \mathrm{~cm}$ depth for MvG parameterization & n_fit_zcm \\
$\overline{\theta_{\mathrm{s}}}$ & $\mathrm{m}^{3} \mathrm{~m}^{-3}$ & Mean $\theta_{\mathrm{s}}$ at $z \mathrm{~cm}$ depth for MvG parameterization & mean_theta_s_zcm \\
$\overline{\theta_{\mathrm{r}}}$ & $\mathrm{m}^{3} \mathrm{~m}^{-3}$ & Mean $\theta_{\mathrm{r} \text { at } z \mathrm{~cm} \text { depth for MvG parameterization }}$ & mean_theta_r_zcm \\
$\bar{L}$ & - & Mean pore connectivity parameter at $z$ cm depth for MvG parameterization & mean_L_zcm \\
$\left(\operatorname{mean}\left(\log _{10} K_{\mathrm{S}}\right)\right)$ & $\mathrm{cm} \mathrm{d}^{-1}$ & Mean saturated hydraulic conductivity at $z$ cm depth & mean_Ks_zcm \\
$\operatorname{var}\left(\log _{10} \hat{\lambda_{i}}\right)$ & - & Scaling parameter variance at $z$ cm depth & var_scaling_zcm \\
$\operatorname{Valid} \operatorname{subpixels}$ & - & Number of valid subpixels for calculating scaling statistics for the $z \mathrm{~cm}$ soil depth & valid_subpixels_zcm \\
\hline
\end{tabular}

in Australia. Smaller regions with high $\hat{\alpha}$ could be traced in Florida and the morainal plains of northern Europe and the Rocky Mountains. The global average of $\hat{n}$ is 1.547 , with a range between 1.174 and $4.33(-)$. The extreme high $\hat{n}$ values are found only in the non-alluvial regions of the Sahara and Rub' al Khali ("Empty Quarter", Arab Peninsula). The relatively high global average of $\hat{n}$ is caused by the same effect that caused the low $\hat{\alpha}$ average in the low bulk density of boreal top soils. Those soils typically are characterized by high organic carbon contents, behave quite differently in hydraulic sense compared to more mineral-dominated soils, and are rarely used to develop classical PTFs. Therefore, independent of the aggregation or up-scaling approaches, more research is needed to adequately parameterize boreal soils by appropriate PTFs.

The global map of mean saturated hydraulic conductivity $\left(\operatorname{mean}\left(\log _{10} K_{\mathrm{S}}\right)\right)$ in Fig. 5 ranges between 0.174 and 3.105 with a global average of $1.784\left(\mathrm{~cm} \mathrm{~d}^{-1}\right)$. Low soilsaturated hydraulic conductivities are located in India, the Sahel, the Mediterranean, central Asia, the Levant and Iran, Texas, the US prairie regions, California and south-central Canada. Highest mean $\left(\log _{10} K_{\mathrm{s}}\right)$ are found in the Sahara and Rub' al Khali, where sandy soils dominate, but also in the upper Amazon Basin (Marthews et al., 2014) and in cold climates.
Figure 6 shows the global map of sub-grid scaling variance calculated from SoilGrids $1 \mathrm{~km}$ data set with a $0.25^{\circ}$ grid reference. Global $\operatorname{var}\left(\log _{10} \hat{\lambda_{i}}\right)$ ranges between $\sim 0$ and 1.574 , with an average value of 0.229 . This shows that large regions, e.g. Siberia, East China, southern coastal provinces of Brazil and Mexico, are relatively homogeneous within individual grid cells. The regions with particularly high subgrid variability are typically transition zones of soils evolved from young sediments. Examples are the holocene morainal plains in northern Europe and Canada, as well as the slopes of high mountains areas of the Andes and Himalayas. Similarly, young deposits of large rivers such as the Amazon and the inner Congo Basin are characterized by high variability. These are the regions where the consideration of the sub-grid variability may have strong impacts on weather prediction and climate simulations.

The final data set is stored in netcdf format in WGS84 projection and contains the information given in Table 1. The file naming convention follows the scheme "Hydraul_Param_BasicSoilMap_PTF_slX", where BasicSoilMap indicates the soil map used for development of the data set (here SoilGrids $1 \mathrm{~km}$ ), PTF indicates the pedotransfer function used (here Schaap) and $X$ indicates the soil layer (sl; in the case of SoilGrids $1 \mathrm{~km}$ the layers 1-7 are available). 

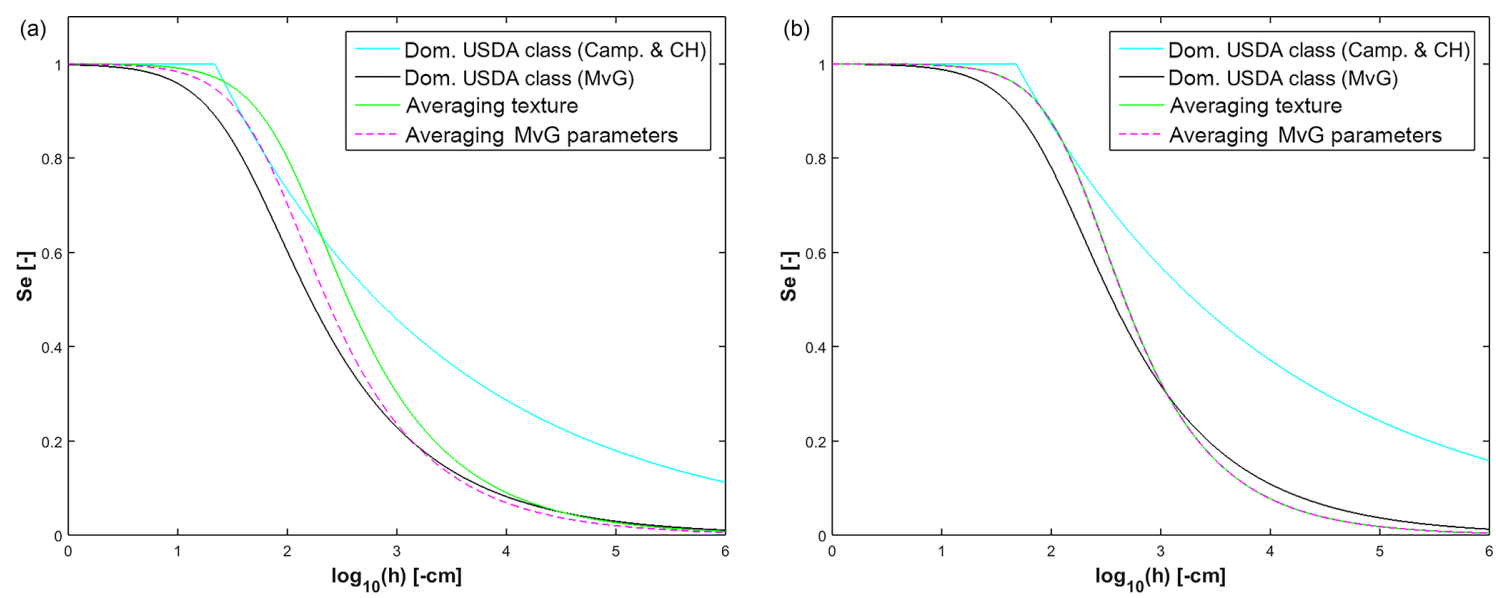

Figure 7. PF curve after applying typical scaling or aggregation methods: by dominant USDA soil class and Clapp and Hornberger parameters for the Brooks and Corey equation, by dominant USDA soil class and MvG equation, by averaging soil texture parameters and then applying ROSETTA PTFs, and by averaging MvG soil hydraulic parameters directly, for Lower Saxony (left) and North Rhine-Westphalia (right).
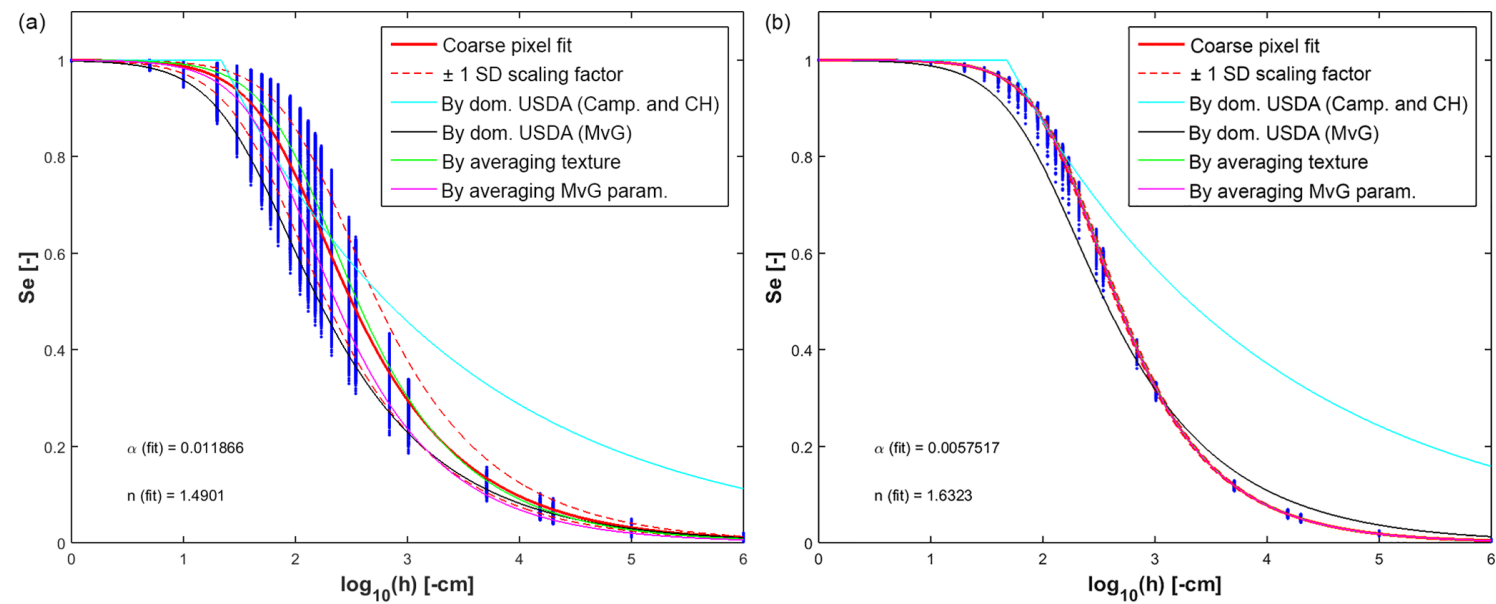

Figure 8. Retention curves for Lower Saxony (left) and North Rhine-Westphalia (right) calculated using different approaches. The coarse pixel fit is the result of the Warrick scaling approach, where $\left(\log _{10} \hat{\lambda_{i}}\right)$ was also estimated. Therefore, $\pm 1 \operatorname{SD}\left(\log _{10} \hat{\lambda_{i}}\right) \operatorname{could}$ also be provided to identify the sub-grid uncertainty. Further retention curves were calculated by dominant USDA class (both for Brooks and Corey with Clapp and Hornberger and for MvG equation), by averaging texture and by averaging MvG parameters. Blue points indicate $S_{\mathrm{e}}$ at standard hydraulic heads for each individual subpixel.

\subsection{Example pixels}

The detailed analysis of the WRC of two example model grid cells after applying a range of typical aggregation methods is shown in Fig. 7. This includes aggregation by averaging soil texture information, averaging MvG soil hydraulic parameters, and by selecting the dominant USDA soil class (both with $\mathrm{MvG}$ and Campbell equations). Averaging soil texture and averaging MvG parameters to a coarser grid caused differences in the WRC for Lower Saxony but showed nearly the same curve for North Rhine-Westphalia. The reasons why textural and MvG parameter averaging yielded the same aggregated WRC in North Rhine-Westphalia are unclear but as Zhu and Mohanty (2002) pointed out, the reliability of $\mathrm{MvG}$ averaging greatly depends on the fine-scale (here $1 \mathrm{~km}$ ) heterogeneity (textural differences), but also on the textural class. Therefore, in the heterogeneous region of Lower Saxony the difference is large which leads to 0.04 higher $S_{\mathrm{e}}$ at $2.5 \log _{10}(h)$ when averaging texture as opposed to averaging $\mathrm{MvG}$ parameters. However, more drastic differences occur when using the dominant USDA soil class to predict coarsescale WRCs, where the Clapp and Hornberger parameterization for the Campbell model results in wetter conditions for all pressure heads than when using the class-representative MvG parameters and the MvG model. 

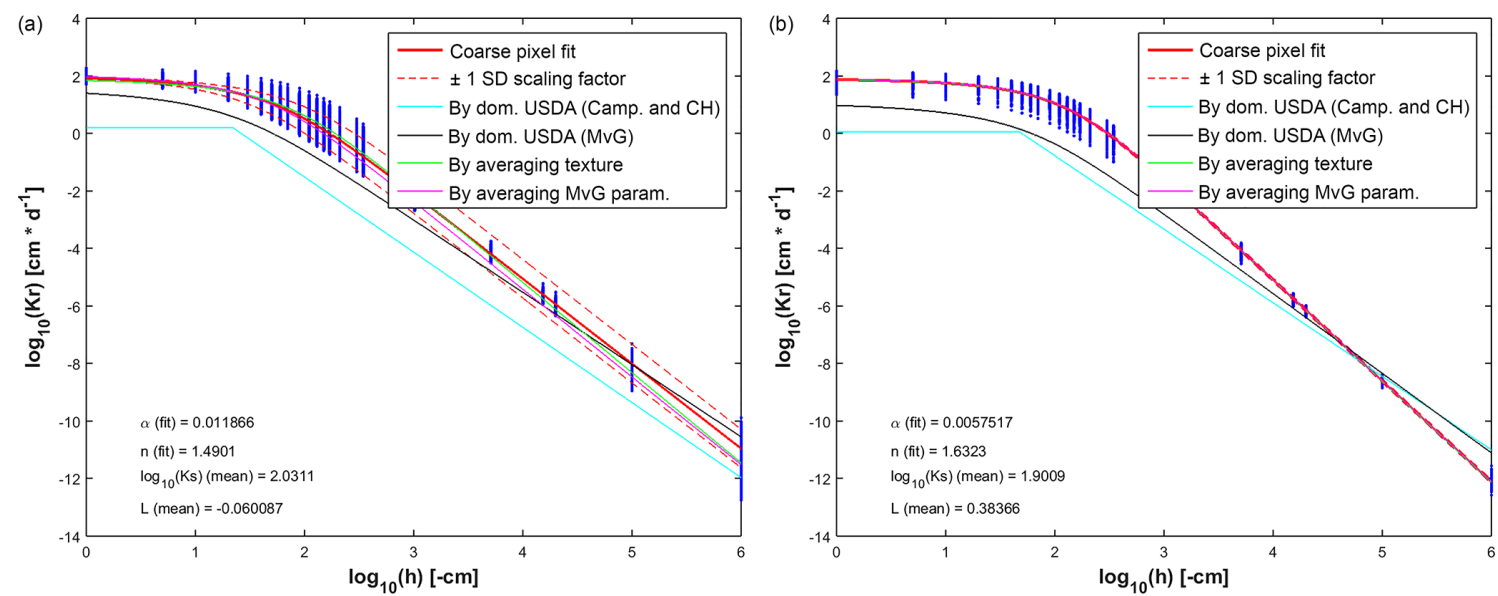

Figure 9. Hydraulic conductivity curves for Lower Saxony (left) and North Rhine-Westphalia (right). The coarse pixel fit is the result of the Warrick scaling approach, where $\left(\log _{10} \hat{\lambda_{i}}\right)$ was also estimated. Therefore, $\pm 1 \operatorname{SD}\left(\log _{10} \hat{\lambda_{i}}\right)$ could also be provided to identify the sub-grid uncertainty. Further hydraulic conductivity curves were calculated by dominant USDA class (both for Brooks and Corey with Clapp and Hornberger and for $\mathrm{MvG}$ equation), by averaging texture and by averaging $\mathrm{MvG}$ parameters. Blue points indicate $\log _{10}\left(K_{\mathrm{r}}\right)$ at standard hydraulic heads for each individual subpixel.
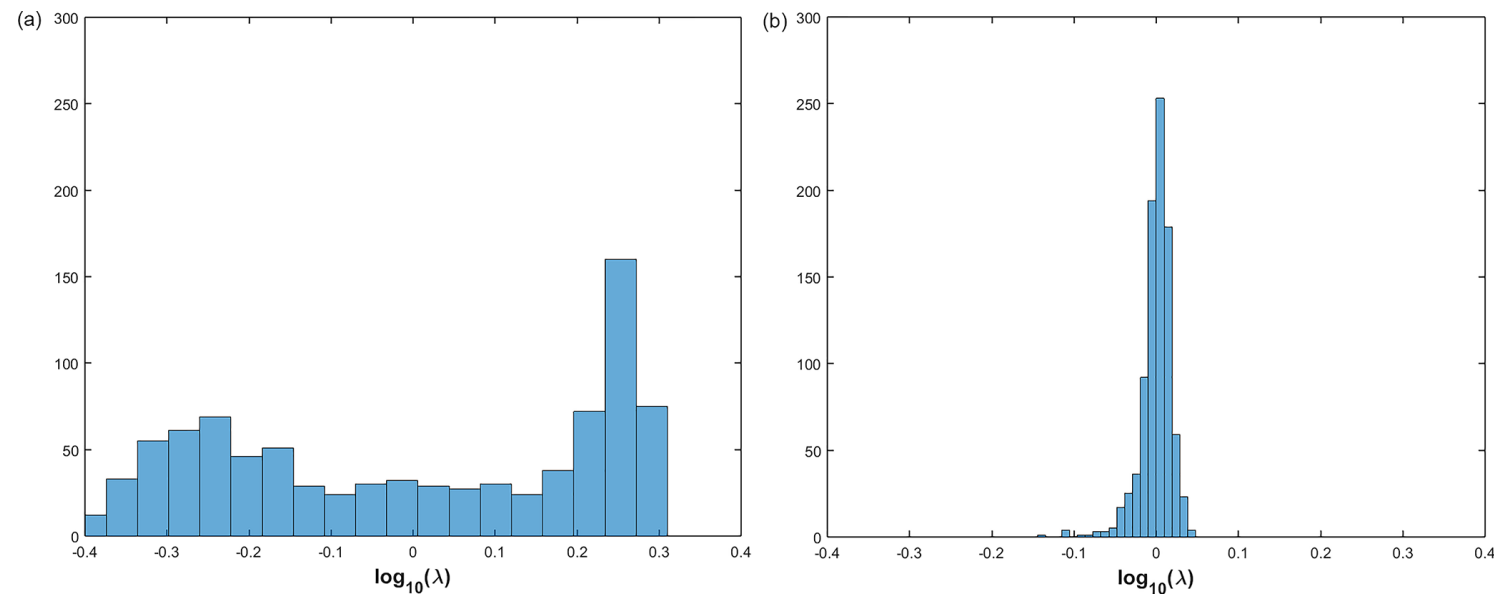

Figure 10. Histograms of the retention scaling parameter $\left(\log _{10} \hat{\lambda}_{i}\right)$ for Lower Saxony (left) and North Rhine-Westphalia (right).

Finally, the WRCs based on the different aggregation approaches (dominant soil class, texture averaging, Warrick scaling) are presented in Fig. 8 for the two example regions. As can be seen, the effective saturation $\left(S_{\mathrm{e}_{i}}\right)$ calculated for the $1 \mathrm{~km}$ sub-pixels at the standard heads of the head vector $\boldsymbol{h}$ (Eq. 3) (blue dots) reflects the natural variability in soil texture and corresponding soil hydraulic properties of the two example regions. This subscale variability is also captured by the standard deviation of the Warrick scaling approach, which is larger for Lower Saxony as compared to North Rhine-Westphalia. This indicates nicely that Warrick scaling is an appropriate approach to capture fine-scale variability and to propagate the fine-scale uncertainty into the larger scale of interest.

A similar pattern of the different scaling methods can be also found for the HCCs presented in Fig. 9. By this Warrick scaling approach, not only can large-scale modelling capture the right aggregated "mean" WRCs and HCCs but also the uncertainty can be taken into account by running the models for the retention/hydraulic characteristics spanned by the variance of the scaling factor.

Finally, we plotted the histograms of the calculated subgrid scaling parameters (Fig. 10). Here it has to be noted that the scaling parameter $\lambda$ was $\log$-transformed with zero mean. Again, the differences in sub-grid heterogeneity of the two example regions become obvious with larger variability in $\lambda$ for Lower Saxony and lower variability for North RhineWestphalia. 

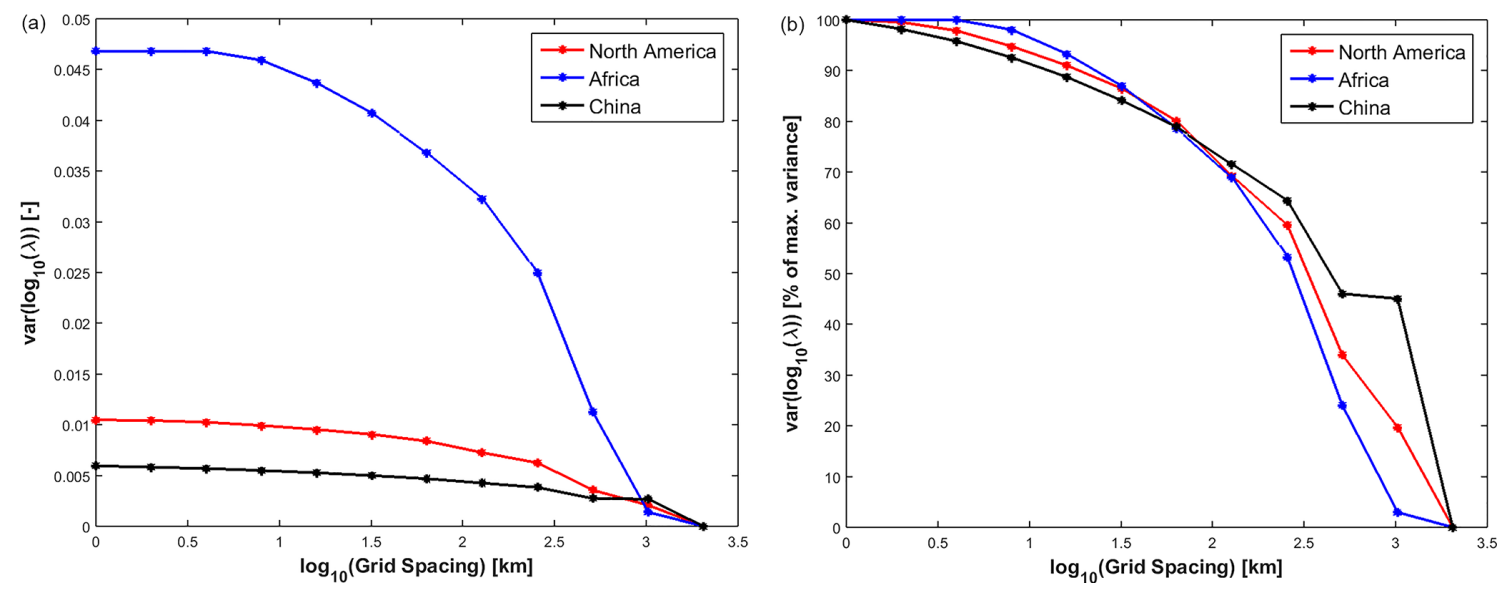

Figure 11. Retention scaling parameter variance $\operatorname{var}\left(\log _{10} \hat{\lambda_{i}}\right)$ for different grid resolutions and regions of interest (North America, Africa and China; see also Fig. 4). (Left) absolute variance and (right) variance normalized as percentage of the maximum variance at $1 \mathrm{~km}$ original SoilGrids $1 \mathrm{~km}$ resolution.

\subsection{Analysing scaling variability for different spatial resolutions}

For the analysis of the scaling variability for different spatial resolutions the mean variance $\left(\operatorname{var}\left(\log _{10} \hat{\lambda_{i}}\right)\right)$ was calculated for different grid resolutions and plotted in Fig. 11. For all three case sites (North America, Africa and China; see also Fig. 3) $\operatorname{var}\left(\log _{10} \hat{\lambda}_{i}\right)$ decreased with decreasing spatial resolution; the absolute scaling parameter variability of the Africa region is largest. This can be explained by the fact that the Sahel is prone to strong seasonal dry-wet cycles, which induces large variability in soil development (Da Costa et al., 2015). On the other hand, the relative decrease of variance with coarser resolution for this region is comparable to the other ones (Fig. 11, right panel).

Interestingly, $\sim 90 \%$ of the variance is still maintained at $16 \mathrm{~km}$ grid size, $\sim 80 \%$ at $64 \mathrm{~km}$, and $\sim 70 \%$ at $128 \mathrm{~km}$. Even at $256 \mathrm{~km}$ spatial resolution, more than $50 \%$ of the variability is accounted for, but a diverging trend between the regions is detectable.

\subsection{Inherent uncertainties}

The use of PTFs and the practice of up-scaling of parameters from $1 \mathrm{~km}$ to grid scales where LSMs or related models such as GCMs are applied; both introduce uncertainty which needs to be discussed. Here it is important to mention that the scaling variance $\operatorname{var}\left(\log _{10} \hat{\lambda_{i}}\right)$ calculated with the proposed approach denotes only the spatial sub-grid variance from $1 \mathrm{~km}$ resolution of SoilGrids $1 \mathrm{~km}$ towards $0.25^{\circ}$ resolution, but this implies no information about the specific uncertainties mentioned above. Moreover, we restricted the analysis to the mean predicted values of SoilGrids $1 \mathrm{~km}$ variables such as texture and bulk density, but the full prediction uncertainty within a confidence interval could be used in an extended approach to estimate the soil hydraulic prop- erty uncertainty. Another source of uncertainty is the use of the log-transform for scaling multiplier in Warrick scaling and averaging the saturated hydraulic conductivity using log transform. The applicability of a PFT to global scale may be limited for specific conditions, because the soil database used to estimate the transfer functions is often regionally limited, so that the extrapolation to soils not included in the statistical analysis introduces large uncertainty (e.g. for boreal soils). Finally, we aimed to provide a consistent data set and therefore derived the HCC from WRC rather than calculating them independently. The new data set was developed and all calculations were made under the hypothesis that spatial variance of WRC and HCC scales with spatial resolution.

\section{Data availability}

The SoilGrids $1 \mathrm{~km}$ data set can be accessed at www.soilgrids. org.

\section{Conclusions and outlook}

Reliable soil hydraulic parameterization is important for global climate model predictions, including climate reanalyses and weather forecast models. State-of-the-art global soil maps can provide basic soil properties at sub-kilometre scale resolution. The transfer of these data towards coarserresolution hydraulic properties has been a topic in soil/land surface up-scaling or aggregation research for several decades. In this paper we present a scaling method based on Miller-Miller similarity theory in the relaxed form of Warrick which was applied to the SoilGrids $1 \mathrm{~km}$ data set to provide parameters for the van Genuchten model of water retention curve (WRC) and the Mualem-van Genuchten model of hydraulic conductivity curve (HCC). These curves are required to solve variably saturated flow in soils us- 
ing Richards' equation. In addition, the sub-grid variability of both WRC and HCC is assessed, which can be of use for model ensemble generation in climate and weather forecast models, or for down-/up-scaling approaches. The final global data set at $0.25^{\circ}$ spatial resolution is available at https://doi.org/10.1594/PANGAEA.870605.

The new data set is presented and analysed at the global scale and in more detail by two different individual pixels differing strongly in textural composition. In comparison to aggregation by using dominant USDA soil classes, averaging soil texture and averaging soil hydraulic parameters, the curve fitting approach provides better estimates of coarsescale water retention and conductivity curves and related parameters. Moreover, the Warrick scaling provides an indicator of sub-grid variability, which is not available from the other methods mentioned above. For three regions different spatial resolutions were analysed according to their ability to represent the soil hydraulic variability of the original SoilGrids database at $1 \mathrm{~km}$ resolution. For all regions a common general loss of variability was observed, with losing $\sim 10 \%$ of the variance at $16 \mathrm{~km}$ grid size, $\sim 20 \%$ at $64 \mathrm{~km}$, and $\sim 30 \%$ at $128 \mathrm{~km}$. This has large implications for the application of global climate models. Process descriptions which are directly influenced by the hydraulic parameterization such as evaporation and infiltration may lose important information about extreme conditions when applying models at too coarse spatial resolution.

The presented analysis has been conducted on twodimensional soil maps, without consideration of vertical relationships between soil layers or horizons. This approach can be easily extended towards a three-dimensional scaling that honours the vertical spatial dependency. A follow-up paper will assess the impact of this data set on water and energy fluxes at the soil surface for global simulations. Similarly, the effect of using other PTFs than Schaap et al. (2001) needs to be evaluated on the global scale as well as the uncertainties introduced during pedotransfer on the scaling parameterization. We plan to provide similar data sets for other PTFs, e.g. of Rawls and Brakensiek (1985), Wösten et al. (1999), Weynants et al. (2009) and Vereecken et al. (1989). A similar approach is planned to provide parameters for the Brooks and Corey equation.

Competing interests. The authors declare that they have no conflict of interest.

Acknowledgements. This study was supported by the Helmholtz Alliance on "Remote Sensing and Earth System Dynamics".

Edited by: Giuseppe M. R. Manzella

Reviewed by: two anonymous referees

\section{References}

Ahuja, L. R., Naney, J. W., and Nielsen, D. R.: Scaling Soil-Water Properties and Infiltration Modeling, Soil Sci. Soc. A. J., 48, 970-973, 1984.

Ballabio, C., Panagos, P., and Monatanarella, L.: Mapping topsoil physical properties at European scale using the LUCAS database, Geoderma, 261, 110-123, https://doi.org/10.1016/j.geoderma.2015.07.006, 2016.

Balsamo, G., Albergel, C., Beljaars, A., Boussetta, S., Brun, E., Cloke, H., Dee, D., Dutra, E., Muñoz-Sabater, J., Pappenberger, F., de Rosnay, P., Stockdale, T., and Vitart, F.: ERAInterim/Land: a global land surface reanalysis data set, Hydrol. Earth Syst. Sci., 19, 389-407, https://doi.org/10.5194/hess-19389-2015, 2015.

Bauer, J., Weihermuller, L., Huisman, J. A., Herbst, M., Graf, A., Sequaris, J. M., and Vereecken, H.: Inverse determination of heterotrophic soil respiration response to temperature and water content under field conditions, Biogeochemistry, 108, 119-134, https://doi.org/10.1007/s10533-011-9583-1, 2012.

Best, M. J., Pryor, M., Clark, D. B., Rooney, G. G., Essery, R. L. H., Ménard, C. B., Edwards, J. M., Hendry, M. A., Porson, A., Gedney, N., Mercado, L. M., Sitch, S., Blyth, E., Boucher, O., Cox, P. M., Grimmond, C. S. B., and Harding, R. J.: The Joint UK Land Environment Simulator (JULES), model description Part 1: Energy and water fluxes, Geosci. Model Dev., 4, 677-699, https://doi.org/10.5194/gmd-4-677-2011, 2011.

Bouma, J.: Using Soil Survey Data for Quantitative Land Evaluation, in: Advances in Soil Science, edited by: Stewart, B. A., Springer US, New York, NY, 177-213, 1989.

Brooks, R. J. and Corey, A. T.: Hydraulic properties of porous media, Colorado State University Fort Collins, CO, USA, Hydrology Papers, 3, 37 pp., 1964.

Cale, W. G., Oneill, R. V., and Gardner, R. H.: Aggregation Error in Non-Linear Ecological Models, J. Theor. Biol., 100, 539-550, 1983.

Campbell, G. S.: A Simple Method for Determining Unsaturated Conductivity From Moisture Retention Data, Soil Sci., 117, 311314, 1974.

Clapp, R. B. and Hornberger, G. M.: Empirical Equations for Some Soil Hydraulic-Properties, Water Resour. Res., 14, 601604, 1978.

Clausnitzer, V., Hopmans, J. W., and Nielsen, D. R.: Simultaneous Scaling of Soil-Water Retention and Hydraulic Conductivity Curves, Water Resour. Res., 28, 19-31, 1992.

Da Costa, P. Y. D., Nguetnkam, J. P., Mvoubou, C. M., Togbe, K. A., Ettien, J. B., and Yao-Kouame, A.: Old landscapes, preweathered materials, and pedogenesis in tropical Africa: How can the time factor of soil formation be assessed in these regions?, Quatern. Int, 376, 47-74, 2015.

Dimitrov, M., Vanderborght, J., Kostov, K. G., Jadoon, K. Z., Weihermuller, L., Jackson, T. J., Bindlish, R., Pachepsky, Y., Schwank, M., and Vereecken, H.: Soil Hydraulic Parameters and Surface Soil Moisture of a Tilled Bare Soil Plot Inversely Derived from L-Band Brightness Temperatures, Vadose Zone J., 13, 1, https://doi.org/10.2136/vzj2013.04.0075, 2014.

Ek, M., and Cuenca, R. H.: Variation in soil parameters: Implications for modeling surface fluxes and atmospheric 
boundary-layer development, Bound.-Lay. Meteorol., 70, 369_ 383, https://doi.org/10.1007/bf00713776, 1994.

Fallico, C., Tarquis, A. M., De Bartolo, S., and Veltri, M.: Scaling analysis of water retention curves for unsaturated sandy loam soils by using fractal geometry, Eur. J. Soil Sci., 61, 425-436, 2010.

Fang, Z. F., Bogena, H., Kollet, S., and Vereecken, H.: Scale dependent parameterization of soil hydraulic conductivity in 3D simulation of hydrological processes in a forested headwater catchment, J. Hydrol., 536, 365-375, 2016.

Hendrayanto, Kosugi, K., and Mizuyama, T.: Scaling hydraulic properties of forest soils, Hydrol. Process., 14, 521-538, 2000.

Hengl, T., de Jesus, J. M., MacMillan, R. A., Batjes, N. H., and Heuvelink, G. B. M.: SoilGrids1km - Global Soil Information Based on Automated Mapping, PLoS ONE, 9, e114788, https://doi.org/10.1371/journal.pone.0114788, 2014.

Hoffmann, H., Zhao, G., Asseng, S., Bindi, M., Biernath, C., Constantin, J., Coucheney, E., Dechow, R., Doro, L., Eckersten, H., Gaiser, T., Grosz, B., Heinlein, F., Kassie, B. T., Kersebaum, K. C., Klein, C., Kuhnert, M., Lewan, E., Moriondo, M., Nendel, C., Priesack, E., Raynal, H., Roggero, P. P., Rotter, R. P., Siebert, S., Specka, X., Tao, F. L., Teixeira, E., Trombi, G., Wallach, D., Weihermuller, L., Yeluripati, J., and Ewert, F.: Impact of Spatial Soil and Climate Input Data Aggregation on Regional Yield Simulations, PLoS ONE, 11, e0151782, https://doi.org/10.1371/journal.pone.0151782, 2016.

Jadoon, K. Z., Weihermuller, L., Scharnagl, B., Kowalsky, M. B., Bechtold, M., Hubbard, S. S., Vereecken, H., and Lambot, S.: Estimation of Soil Hydraulic Parameters in the Field by Integrated Hydrogeophysical Inversion of TimeLapse Ground-Penetrating Radar Data, Vadose Zone J., 11, 4, https://doi.org/10.2136/vzj2011.0177, 2012.

Jana, R. B. and Mohanty, B. P.: Enhancing PTFs with remotely sensed data for multi-scale soil water retention estimation, J. Hydrol., 399, 201-211, 2011.

Kuhnert, M., Yeluripati, J., Smith, P., Hoffmann, H., van Oijen, M., Constantin, J., Coucheney, E., Dechow, R., Eckersten, H., Gaiser, T., Grosz, B., Haas, E., Kersebaum, K.-C., Kiese, R., Klatt, S., Lewan, E., Nendel, C., Raynal, H., Sosa, C., Specka, X., Teixeira, E., Wang, E., Weihermüller, L., Zhao, G., Zhao, Z., Ogle, S., and Ewert, F.: Impact analysis of climate data aggregation at different spatial scales on simulated net primary productivity for croplands, Eur. J. Agron., 88, 41-52, https://doi.org/10.1016/j.eja.2016.06.005, 2016.

Liang, X., Lettenmaier, D. P., Wood, E. F., and Burges, S. J.: A Simple Hydrologically Based Model of Land-Surface Water and Energy Fluxes for General-Circulation Models, J. Geophys. Res., 99, 14415-14428, 1994.

Liao, K., Xu, S., Wu, J., and Zhu, Q.: Uncertainty analysis for largescale prediction of the van Genuchten soil-water retention parameters with pedotransfer functions, Soil Res., 52, 431-442, 2014.

Marquardt, D. W.: An Algorithm for Least-Squares Estimation of Nonlinear Parameters, J. Soc. Ind. Appl. Math., 11, 431-441, 1963.

Marthews, T. R., Quesada, C. A., Galbraith, D. R., Malhi, Y., Mullins, C. E., Hodnett, M. G., and Dharssi, I.: Highresolution hydraulic parameter maps for surface soils in tropical South America, Geosci. Model Dev., 7, 711-723, https://doi.org/10.5194/gmd-7-711-2014, 2014.
Millan, H. and Gonzalez-Posada, M.: Modelling soil water retention scaling. Comparison of a classical fractal model with a piecewise approach, Geoderma, 125, 25-38, 2005.

Miller, E. E. and Miller, R. D.: Physical Theory for Capillary Flow Phenomena, J. Appl. Phys., 27, 324-332, 1956.

Montzka, C., Moradkhani, H., Weihermüller, L., Hendricks Franssen, H.-J., Canty, M., and Vereecken, H.: Hydraulic parameter estimation by remotely-sensed top soil moisture observations with the particle filter, J. Hydrol., 399, 410-421, https://doi.org/10.1016/j.jhydrol.2011.01.020, 2011.

Ngo-Duc, T., Laval, K., Ramillien, G., Polcher, J., and Cazenave, A.: Validation of the land water storage simulated by Organising Carbon and Hydrology in Dynamic Ecosystems (ORCHIDEE) with Gravity Recovery and Climate Experiment (GRACE) data, Water Resources Resour. Res., 43, W04427, https://doi.org/10.1029/2006WR004941, 2007.

Niu, G. Y., Yang, Z. L., Mitchell, K. E., Chen, F., Ek, M. B., Barlage, M., Kumar, A., Manning, K., Niyogi, D., Rosero, E., Tewari, M., and Xia, Y. L.: The community Noah land surface model with multiparameterization options (Noah-MP): 1. Model description and evaluation with local-scale measurements, J. Geophys. Res., 116, D12109, https://doi.org/10.1029/2010JD015139, 2011

Oleson, K. W., Niu, G. Y., Yang, Z. L., Lawrence, D. M., Thornton, P. E., Lawrence, P. J., Stöckli, R., Dickinson, R. E., Bonan, G. B., Levis, S., Dai, A., and Qian, T.: Improvements to the Community Land Model and their impact on the hydrological cycle, J. Geophys. Res., 113, G01021, https://doi.org/10.1029/2007JG000563, 2008.

Pachepsky, Y. A., Shcherbakov, R. A., and Korsunskaya, L. P.: Scaling of Soil-Water Retention Using a Fractal Model, Soil Sci., 159, 99-104, 1995.

Pierce, L. L. and Running, S. W.: The Effects of Aggregating Subgrid Land-Surface Variation on Large-Scale Estimates of Net Primary Production, Landscape Ecol., 10, 239-253, 1995.

Rastetter, E. B., King, A. W., Cosby, B. J., Hornberger, G. M., Oneill, R. V., and Hobbie, J. E.: Aggregating Fine-Scale Ecological Knowledge to Model Coarser-Scale Attributes of Ecosystems, Ecol. Appl., 2, 55-70, 1992.

Rawls, W. J. and Brakensiek, D. L.: Prediction of soil water properties for hydrologic modelling, American Society of Civil Engineers, 293-299, 1985.

Reynolds, C. A., Jackson, T. J., and Rawls, W. J.: Estimating soil water-holding capacities by linking the Food and Agriculture Organization soil map of the world with global pedon databases and continuous pedotransfer functions, Water Resour. Res., 36, 3653-3662, 2000.

Rodell, M., Houser, P. R., Jambor, U., Gottschalck, J., Mitchell, K., Meng, C. J., Arsenault, K., Cosgrove, B., Radakovich, J., Bosilovich, M., Entin, J. K., Walker, J. P., Lohmann, D., and Toll, D.: The global land data assimilation system, B. Am. Meteorol. Soc., 85, 381-394, 2004.

Russo, D. and Bresler, E.: Scaling Soil Hydraulic-Properties of a Heterogeneous Field, Soil Sci. Soc. Am. J., 44, 681-684, 1980.

Schaap, M. G., Leij, F. J., and van Genuchten, M. T.: ROSETTA: a computer program for estimating soil hydraulic parameters with hierarchical pedotransfer functions, J. Hydrol., 251, 163-176, 2001.

Scharnagl, B., Vrugt, J. A., Vereecken, H., and Herbst, M.: Inverse modelling of in situ soil water dynamics: investigat- 
ing the effect of different prior distributions of the soil hydraulic parameters, Hydrol. Earth Syst. Sci., 15, 3043-3059, https://doi.org/10.5194/hess-15-3043-2011, 2011.

Scheinost, A. C., Sinowski, W., and Auerswald, K.: Regionalization of soil water retention curves in a highly variable soilscape. 1. Developing a new pedotransfer function, Geoderma, 78, 129143, 1997.

Shu, Q. S., Liu, Z. X., and Si, B. C.: Characterizing Scale- and Location-Dependent Correlation of Water Retention Parameters with Soil Physical Properties Using Wavelet Techniques, J. Environ. Qual., 37, 2284-2292, 2008.

Simmons, C. S., Nielsen, D. R., and Biggar, J. W.: Scaling of FieldMeasured Soil-Water Properties, Hilgardia, 47, 77-173, 1979.

Tillotson, P. M. and Nielsen, D. R.: Scale Factors in Soil Science, Soil Sci. Soc. Am. J., 48, 953-959, 1984.

Toth, B., Weynants, M., Nemes, A., Mako, A., Bilas, G., and Toth, G.: New generation of hydraulic pedotransfer functions for $\mathrm{Eu}-$ rope, Eur. J. Soil Sci., 66, 226-238, 2015.

Toth, G., Jones, A., and Montanarella, L.: LUCAS Topsoil Survey. Methodology, data and results, Publications Office of the European Union, Luxembourg, 2013.

Tuli, A., Kosugi, K., and Hopmans, J. W.: Simultaneous scaling of soil water retention and unsaturated hydraulic conductivity functions assuming lognormal pore-size distribution, Adv. Water Resour., 24, 677-688, 2001.

van Dam, J. C., Groenendijk, P., Hendriks, R. F. A., and Kroes, J. G.: Advances of modeling water flow in variably saturated soils with SWAP, Vadose Zone J., 7, 640-653, 2008.

Van Engelen, V. and Dijkshoorn, J.: Global and National Soils and Terrain Digital Databases (SOTER), Procedures Manual, version 2.0, Wageningen, The Netherlands, 192 pp., 2012.

van Genuchten, M. T.: A Closed Form Equation for Predicting the Hydraulic Conductivity of Unsaturated Soils, Soil Sci. Soc. Am. J., 44, 892-898, 1980.

Vereecken, H., Maes, J., Feyen, J., and Darius, P.: Estimating the Soil-Moisture Retention Characteristic from Texture, BulkDensity, and Carbon Content, Soil Sci., 148, 389-403, 1989.

Vereecken, H., Weynants, M., Javaux, M., Pachepsky, Y., Schaap, M. G., and van Genuchten, M. T.: Using Pedotransfer Functions to Estimate the van Genuchten-Mualem Soil Hydraulic Properties: A Review, Vadose Zone J., 9, 795-820, 2010.

Vereecken, H., Schnepf, A., Hopmans, J. W., Javaux, M., Or, D., Roose, T., Vanderborght, J., Young, M. H., Amelung, W., Aitkenhead, M., Allison, S. D., Assouline, S., Baveye, P., Berli, M., Brüggemann, N., Finke, P., Flury, M., Gaiser, T., Govers, G., Ghezzehei, T., Hallett, P., Hendricks Franssen, H. J., Heppell, J., Horn, R., Huisman, J. A., Jacques, D., Jonard, F., Kollet, S., Lafolie, F., Lamorski, K., Leitner, D., McBratney, A., Minasny, B., Montzka, C., Nowak, W., Pachepsky, Y., Padarian, J., Romano, N., Roth, K., Rothfuss, Y., Rowe, E. C., Schwen, A., Šimůnek, J., Tiktak, A., Van Dam, J., van der Zee, S. E. A. T. M., Vogel, H. J., Vrugt, J. A., Wöhling, T., and Young, I. M.: Modeling Soil Processes: Review, Key Challenges, and New Perspectives, Vadose Zone J., 15, 5, https://doi.org/10.2136/vzj2015.09.0131, 2016.
Verhoef, A. and Egea, G.: Modeling plant transpiration under limited soil water: Comparison of different plant and soil hydraulic parameterizations and preliminary implications for their use in land surface models, Agr. Forest Meteorol., 191, 22-32, 2014.

Walko, R. L. and Avissar, R.: The Ocean-Land-Atmosphere Model (OLAM). Part I: Shallow-Water Tests, Mon. Weather Rev., 136, 4033-4044, 2008.

Walters, D. N., Williams, K. D., Boutle, I. A., Bushell, A. C., Edwards, J. M., Field, P. R., Lock, A. P., Morcrette, C. J., Stratton, R. A., Wilkinson, J. M., Willett, M. R., Bellouin, N., BodasSalcedo, A., Brooks, M. E., Copsey, D., Earnshaw, P. D., Hardiman, S. C., Harris, C. M., Levine, R. C., MacLachlan, C., Manners, J. C., Martin, G. M., Milton, S. F., Palmer, M. D., Roberts, M. J., Rodríguez, J. M., Tennant, W. J., and Vidale, P. L.: The Met Office Unified Model Global Atmosphere 4.0 and JULES Global Land 4.0 configurations, Geosci. Model Dev., 7, 361-386, https://doi.org/10.5194/gmd-7-361-2014, 2014.

Wang, Z. Y., Shu, Q. S., Liu, Z. X., and Si, B. C.: Scaling analysis of soil water retention parameters and physical properties of a Chinese agricultural soil, Aust. J. Soil Res., 47, 821-827, 2009.

Warrick, A. W., Mullen, G. J., and Nielsen, D. R.: Scaling FieldMeasured Soil Hydraulic-Properties Using a Similar Media Concept, Water Resour. Res., 13, 355-362, 1977.

Weynants, M., Vereecken, H., and Javaux, M.: Revisiting Vereecken Pedotransfer Functions: Introducing a Closed-Form Hydraulic Model, Vadose Zone J., 8, 86-95, 2009.

Wösten, J. H. M., Lilly, A., Nemes, A., and Le Bas, C.: Development and use of a database of hydraulic properties of European soils, Geoderma, 90, 169-185, 1999.

Xue, Y. K., Zeng, F. J., and Schlosser, C. A.: SSiB and its sensitivity to soil properties - A case study using HAPEX-Mobilhy data, Global Planet Change, 13, 183-194, 1996.

Zeleke, T. B. and Si, B. C.: Wavelet-based multifractal analysis of field scale variability in soil water retention, Water Resour. Res., 43, W07446, https://doi.org/10.1029/2006WR004957, 2007.

Zhu, J. T. and Mohanty, B. P.: Spatial Averaging of van Genuchten Hydraulic Parameters for Steady-State Flow in Heterogeneous Soils: A Numerical Study, Vadose Zone J., 1, 261-272, 2002. 